\title{
Role of interleukin 6 and highly sensitive C-reactive protein in diabetic nephropathy
} Alshabrawy M. Abdelnabi, Ayman M.E.M. Sadek

Internal Medicine Department, Zagazig University, Zagazig, Egypt

Correspondence to Ayman M.E.M. Sadek, MD, Shoubak Basta, Zagazig, Shakia, 44519 Egypt.

Tel: +20 122138 7405; e-mails: amedms@gmail.com, ayman.sadek@zu.edu.eg

Received 24 April 2018

Accepted 9 July 2018

The Egyptian Journal of Internal Medicine 2018, 30:103-109

\section{Context}

The pathogenesis of diabetic nephropathy (DN) is still incompletely understood. Few studies have linked the cellular inflammatory markers, interleukin 6 (IL-6) and highly sensitive C-reactive protein (hs-CRP), to the development of DN.

Aim

We aimed to explore the link among IL-6, hs-CRP, and grades of DN in both types of diabetes mellitus (DM).

\section{Settings and design}

We carried out a case-control study on participants selected from the outpatient clinic of Internal Medicine Department.

\section{Patients and methods}

We worked on 91 participants, comprising 78 patients and 13 controls. The patient group was further subdivided into two subgroups: subgroup I [39 patients type $1 \mathrm{DM}$ (T1DM)] and subgroup II [39 patients type 2 DM (T2DM)]. Each subgroup was categorized according to the urinary albumin excretion rate into three divisions: $A$ ( $<20 \mu \mathrm{g} / \mathrm{min})$, B $(20-200 \mu \mathrm{g} / \mathrm{min})$, and C ( $>200 \mu \mathrm{g} / \mathrm{min})$. We applied history taking, clinical examination, routine investigation, and IL-6 with hs-CRP testing to all participants.

\section{Statistical analysis}

We used Shapiro-Wilk test, $\chi^{2}$ test, Student's $t$ test, one-way analysis of variance, Kruskal-Wallis test, least significant difference test, and Pearson's correlation coefficient for data analysis.

\section{Results}

Despite the significant difference of laboratory data between patient and control groups, least significant difference analysis revealed a nonsignificant difference between patients with T1DM and those with T2DM. On the level of the in-groups analysis, the most significant key players were hs-CRP and IL- 6 among the three urinary albumin excretion rate categories of patients with T1DM and T2DM, with $P$ values less than 0.01 .

\section{Conclusions}

We concluded that IL-6 and hs-CRP might be used as sensitive markers for the development of DN.

\section{Keywords:}

C-reactive protein, diabetic nephropathy, interleukin 6

Egypt J Intern Med 30:103-109

(C) 2018 The Egyptian Journal of Internal Medicine 1110-7782

\section{Introduction}

The pathogenesis of diabetic nephropathy (DN) is still incompletely understood [1].

Cellular inflammatory markers like interleukin 6 (IL-6) and highly sensitive C-reactive protein (hs-CRP) are elevated in tissue damage [2,3], especially in patients without DN over the patients with DN [4].

Scant studies have linked these markers to DN in type 1 (T1) or type 2 (T2) diabetes mellitus (DM) [5-9].

We aimed to explore the link among IL-6, hs-CRP, and grades of DN in both types of DM.

\section{Patients and methods}

\section{Study design}

We conducted a case-control study.

\section{Settings}

We carried out this work on participants selected from the outpatient clinic of Internal Medicine Department in the period from October 2016 to October 2017.

This is an open access journal, and articles are distributed under the terms of the Creative Commons Attribution-NonCommercial-ShareAlike 4.0 License, which allows others to remix, tweak, and build upon the work non-commercially, as long as appropriate credit is given and the new creations are licensed under the identical terms. 


\section{Participants}

We worked on 91 participants, comprising 78 patients and 13 sex-matched controls. The patient group was further allocated into two subgroups according to the type of diabetes: subgroup I (39 patients) represented T1DM and subgroup II (39 patients) represented T2DM.

\section{Sampling}

The estimated sample size was 91 patients at $80 \%$ power and 95\% confidence interval (CI) (Open Epi).

\section{Ethical clearance}

We took an informed consent from the patients who participated in the study. We obtained approval for performing this study from Institutional Review Board.

\section{Inclusion criteria}

We considered participants with T1DM and T2DM of both sex, with age more than or equal to 13 years, for inclusion.

\section{Exclusion criteria}

We excluded patients with proteinuria from causes other than diabetes, acute infections, malignancies, smoking, and obstructive uropathy.

\section{Process}

We categorized the patient subgroups, according to the urinary albumin excretion rate (UAER), into three sub-subgroups (13 patients in each one). Subgroup A with UAER was less than $20 \mu \mathrm{g} / \mathrm{min}$, subgroup B with UAER was ranging from 20 to $200 \mu \mathrm{g} / \mathrm{min}$, and in subgroup C with UAER was more than $200 \mu \mathrm{g} / \mathrm{min}$. The control group contained 13 normal individuals.

We subjected all the participants to full history taking, thorough clinical examination, routine laboratory investigations [including fasting blood glucose, $2 \mathrm{~h}$ postprandial blood glucose, glycated hemoglobin A1c (HbA1c), lipid profile, and kidney functions], and special tests (including UAER measured by a spectrophotometer, and ELISA for hs-CRP and serum IL-6).

\section{Statistical analysis}

We analyzed the data using statistical package for the social sciences, version 20.0 for Windows (SPSS; SPSS Inc., Chicago, Illinois, USA). We expressed continuous variables as the mean $\pm \mathrm{SD}$, median, and range, whereas the categorical variables as a number (percentage). We checked continuous variables for normality by using Shapiro-Wilk test. We analyzed normally distributed data between two groups by using independent Student's $t$ test. We used one-way analysis of variance to compare normally distributed variables in three groups or more. We used Kruskal-Wallis test to compare nonnormally distributed variables in three groups or more. We used Fisher's least significant difference (LSD) test according to the homogeneity of variances. Percentages of categorical variables were compared using the $\chi^{2}$ test. We used Pearson's correlation coefficient to assess the correlation between IL-6, hs-CRP, and study parameters, with positive sign as an indication for direct correlation and negative sign as an indication for inverse correlation. Moreover, we consider values near to 1 as strong correlation and values near 0 as weak correlation.

\section{Results}

The patient group included 78 participants who were allocated to subgroup I (T1DM) and subgroup II (T2DM). Subgroup I included 39 patients, comprising 23 male and 16 female, with age ranging from 18 to 33 years old and duration of diabetes ranging from 6.5 to 18 years. Subgroup II included 39 patients, comprising 20 male and 19 female, with age ranging from 46 to 62 years old and duration of diabetes ranging from 6 to 17 years. Control group included 13 participants, comprising seven male and six female, with age ranging from 13 to 50 years old.

Table 1 Demographic and clinical data of the studied groups

\begin{tabular}{|c|c|c|c|}
\hline \multirow[b]{2}{*}{ Variables } & \multirow[b]{2}{*}{ Control $(N=13)[n(\%)]$} & \multicolumn{2}{|c|}{ Patients } \\
\hline & & Subgroup I $(N=39)[n(\%)]$ & Subgroup II $(N=39)[n(\%)]$ \\
\hline \multicolumn{4}{|l|}{ Sex } \\
\hline Male & $7(53.8)$ & $23(59)$ & $20(51.3)$ \\
\hline \multirow[t]{3}{*}{ Female } & $6(46.2)$ & $16(41)$ & $19(48.7)$ \\
\hline & Mean \pm SD & Mean \pm SD & Mean \pm SD \\
\hline & $25.69 \pm 7.88$ & $25.45 \pm 4.65$ & $53.49 \pm 4.07$ \\
\hline Age (years) & - & $11.55 \pm 3.11$ & $10.72 \pm 3.04$ \\
\hline Duration of DM (years) & $95.08 \pm 3.66$ & $103.78 \pm 12.34$ & $102.1 \pm 12.08$ \\
\hline Waist-hip ratio & $111.54 \pm 7.74$ & $132.18 \pm 7.90$ & $129.78 \pm 12.54$ \\
\hline Systolic pressure (mmHg) & $72.69 \pm 5.63$ & $84.49 \pm 8.33$ & $81.03 \pm 7.88$ \\
\hline Diastolic pressure $(\mathrm{mmHg})$ & $7(53.8)$ & $23(59)$ & $20(51.3)$ \\
\hline
\end{tabular}

DM, diabetes mellitus. 
Demographic and clinical data are demonstrated in Table 1.

Table 2 showed a significant difference between the patient subgroups and control group regarding all laboratory data. However, LSD clarified the absence of difference in all these parameters between subgroup I and subgroup II.

Performing in-group analysis in subgroup I revealed a significant difference between the three studied subsubgroups of T1DM regarding creatinine, urea, UAER, hs-CRP, and IL-6. Regarding LSD, there were statistical differences in UAER, hs-CRP, and IL-6 between all sub-subgroups, but creatinine and urea showed difference in subgroup IC when compared with both subgroup IA and subgroup IB, with no difference between subgroup IA and subgroup IB (Table 3). We found a similar result in subgroup II in-group analysis (Table 4). When we compared subgroups IA with IIA, IB with IIB, and IC with IIC, we could not reveal a statistical difference (supplementary tables 1, 2, and 3).

We applied Pearson's correlation to both inflammatory markers to explore their link with other parameters. Regarding hs-CRP, as demonstrated in the Table 5, both patient subgroups showed a positive correlation with disease duration, blood pressure (systolic and diastolic), kidney functions (urea and creatinine), UAER, and IL-6, whereas there were no correlations in control group. Regarding IL-6, as demonstrated in Table 6 , both patient subgroups showed a positive correlation with disease duration, waist-hip ratio, blood pressure (systolic and diastolic, except for subgroup I, where there was no correlation with diastolic pressure), kidney functions, UAER, and hs-CRP, whereas there were no correlations in control group.

\section{Discussion}

The net results of our study were the significant difference of the laboratory data between patient and control groups; however, LSD analysis revealed a nonsignificant difference between patients with T1DM and T2DM. On the level of in-groups analysis, the most significant key players were hsCRP and IL-6 between the three UAER categories of patients with T1DM and T2DM, with $P$ values less than 0.01 .

We tried to explain if there was an association between hs-CRP and IL-6 and grades of DN in the two types of

Table 2 Comparison of laboratory results of the studied groups

\begin{tabular}{|c|c|c|c|c|c|c|}
\hline \multirow[t]{2}{*}{ Variables } & \multirow[t]{2}{*}{ Control $(N=13)$} & \multicolumn{2}{|c|}{ Patients } & \multirow[t]{2}{*}{ Test } & \multirow[t]{2}{*}{$P$} & \multirow[t]{2}{*}{ LSD } \\
\hline & & Subgroup I $(N=39)$ & Subgroup II $(N=39)$ & & & \\
\hline \multicolumn{7}{|c|}{ Fasting blood glucose (mg/dl) } \\
\hline Mean \pm SD & $86.46 \pm 3.26$ & $163.9 \pm 37.7$ & $163.56 \pm 38.6$ & $F^{\mathrm{a}} 26.45$ & $<0.001$ & $<0.001^{\mathrm{b}}<0.001^{\mathrm{c}} 0.97^{\mathrm{d}}$ \\
\hline Range & $79-90$ & $85-250$ & $85-245$ & & & \\
\hline \multicolumn{7}{|c|}{$2 \mathrm{~h}$ postprandial (mg/dl) } \\
\hline Mean \pm SD & $116.77 \pm 11.4$ & $257.3 \pm 40.5$ & $251.9 \pm 39.6$ & $F^{\mathrm{a}} 75.54$ & $<0.001$ & $<0.001^{\mathrm{b}}<0.001^{\mathrm{c}} 0.53^{\mathrm{d}}$ \\
\hline Range & $98-130$ & $210-350$ & $205-340$ & & & \\
\hline \multicolumn{7}{|l|}{$\mathrm{HbA} 1 \mathrm{c} \%$} \\
\hline Mean $\pm S D$ & $4.85 \pm 0.28$ & $7.77 \pm 1.03$ & $7.70 \pm 0.95$ & $F^{\mathrm{a}} 54.35$ & $<0.001$ & $<0.001^{b}<0.001^{c} 0.76^{d}$ \\
\hline Range & $4.5-5.3$ & $6-12.9$ & $6.4-12.5$ & & & \\
\hline \multicolumn{7}{|c|}{ Creatinine (mg/dl) } \\
\hline Mean \pm SD & $0.88 \pm 0.14$ & $1.19 \pm 0.26$ & $1.14 \pm 0.25$ & $F^{\mathrm{a}} 8.17$ & $<0.001$ & $<0.001^{\mathrm{b}}<0.001^{\mathrm{b}} 0.31^{\mathrm{d}}$ \\
\hline Range & $0.65-1.1$ & $0.7-1.7$ & $0.7-1.6$ & & & \\
\hline \multicolumn{7}{|l|}{ Urea (mg/dl) } \\
\hline Mean \pm SD & $27.15 \pm 5.94$ & $35.23 \pm 10.4$ & $34.49 \pm 10.4$ & $F^{\mathrm{a}} 3.42$ & 0.04 & $<0.001^{\mathrm{b}}<0.001^{\mathrm{c}} 0.74^{\mathrm{d}}$ \\
\hline Range & $20-40$ & $20-60$ & $20-60$ & & & \\
\hline \multicolumn{7}{|c|}{ Urinary albumin excretion rate $(\mu \mathrm{g} / \mathrm{min})$} \\
\hline Mean \pm SD & $6.38 \pm 3.07$ & $226.4 \pm 202.2$ & $218.8 \pm 198.7$ & $K^{\mathrm{a}, \mathrm{e}} 26.08$ & $<0.001$ & $<0.001^{\mathrm{b}}<0.001^{\mathrm{c}} 0.86^{\mathrm{d}}$ \\
\hline Range & $2-10$ & $5-640$ & $4-620$ & & & \\
\hline \multicolumn{7}{|c|}{ Highly sensitive C-reactive protein (mg/l) } \\
\hline Mean \pm SD & $1.32 \pm 0.42$ & $4.11 \pm 1.83$ & $4 \pm 1.78$ & $K^{\mathrm{e}} 28.89$ & $<0.001$ & $<0.001^{\mathrm{b}}<0.001^{\mathrm{c}} 0.78^{\mathrm{d}}$ \\
\hline Range & $0.7-2$ & $0.9-8.9$ & $0.9-8.7$ & & & \\
\hline \multicolumn{7}{|c|}{ Interleukin 6 (pg/ml) } \\
\hline Mean \pm SD & $1.97 \pm 0.33$ & $2.66 \pm 0.77$ & $2.57 \pm 0.75$ & $F^{\mathrm{a}} 4.72$ & 0.01 & $0.003^{b} 0.01^{c} 0.56^{d}$ \\
\hline Range & $1.35-2.45$ & $1.3-4.1$ & $1.2-4$ & & & \\
\hline
\end{tabular}

${ }^{a}$ Analysis of variance test. ${ }^{b}$ Control versus subgroup I. ${ }^{c}$ Control versus subgroup II. ${ }^{d}$ Subgroup I versus subgroup II. ${ }^{e}$ Kruskal-Wallis test. HbA1c, glycated hemoglobin A1c; LSD, least significant difference. It means that the value is statistically significant $(P<0.05)$. 
Table 3 Comparison of laboratory results of the type 1 diabetes mellitus subgroups

\begin{tabular}{|c|c|c|c|c|c|c|}
\hline Variables & Subgroup IA $(N=13)$ & Subgroup IB $(N=13)$ & Subgroup IC $(N=13)$ & Test & $P$ & LSD \\
\hline \multicolumn{7}{|c|}{ Fasting blood glucose (mg/dl) } \\
\hline Mean \pm SD & $152.7 \pm 15.7$ & $179.8 \pm 49.4$ & $159.2 \pm 37.2$ & $F^{\mathrm{a}} 1.91$ & 0.16 & $0.06^{\mathrm{b}} 0.65^{\mathrm{c}} 0.16^{\mathrm{d}}$ \\
\hline Range & $129-178$ & $85-250$ & $109-250$ & & & \\
\hline \multicolumn{7}{|c|}{$2 \mathrm{~h}$ postprandial (mg/dl) } \\
\hline Mean \pm SD & $245 \pm 32.4$ & $271.5 \pm 44.9$ & $255.4 \pm 42$ & $F^{\mathrm{a}} 1.34$ & 0.25 & $0.10^{b} 0.51^{c} 0.31^{d}$ \\
\hline Range & 210-290 & $210-350$ & $210-330$ & & & \\
\hline \multicolumn{7}{|l|}{$\mathrm{HbA} 1 \mathrm{c} \%$} \\
\hline Mean \pm SD & $7.44 \pm 0.21$ & $7.85 \pm 1.69$ & $8.02 \pm 0.51$ & $F^{\mathrm{a}} 1.08$ & 0.35 & $0.32^{b} 0.16^{c} 0.38^{d}$ \\
\hline Range & $7-7.6$ & $6-12.9$ & $6.9-8.6$ & & & \\
\hline \multicolumn{7}{|c|}{ Creatinine (mg/dl) } \\
\hline Mean \pm SD & $1 \pm 0.16$ & $1.15 \pm 0.23$ & $1.42 \pm 0.18$ & $F^{\mathrm{a}} 15.83$ & $<0.001$ & $0.05^{b}<0.001^{c} \mathbf{0 . 0 0 1 ^ { d }}$ \\
\hline Range & $0.70-1.2$ & $0.8-1.6$ & $1.1-1.7$ & & & \\
\hline \multicolumn{7}{|l|}{ Urea (mg/dl) } \\
\hline Mean \pm SD & $28.7 \pm 5.95$ & $30.53 \pm 6.57$ & $46.46 \pm 7.53$ & $F^{\mathrm{a}} 27.52$ & 0.04 & $0.49^{\mathrm{b}}<\mathbf{0 . 0 0 1 ^ { c }}<\mathbf{0 . 0 0 1 ^ { \mathrm { d } }}$ \\
\hline Range & $20-40$ & $20-40$ & $35-60$ & & & \\
\hline \multicolumn{7}{|c|}{ Urinary albumin excretion rate $(\mu \mathrm{g} / \mathrm{min})$} \\
\hline Mean \pm SD & $12.54 \pm 4.03$ & $189.62 \pm 40.6$ & $477.9 \pm 93.6$ & $K^{\mathrm{e}} 205.6$ & $<0.001$ & $<0.001^{\mathrm{b}}<0.001^{\mathrm{c}}<0.001^{\mathrm{d}}$ \\
\hline Range & $5-19$ & $130-200$ & $230-640$ & & & \\
\hline \multicolumn{7}{|c|}{ Highly sensitive C-reactive protein (mg/l) } \\
\hline Mean \pm SD & $2.62 \pm 0.76$ & $4.1 \pm 0.84$ & $5.62 \pm 2.12$ & $K^{\mathrm{e}} 21.75$ & $<0.001$ & $0.01^{b}<0.001^{c} 0.008^{d}$ \\
\hline Range & $0.9-3.7$ & $2.5-5.5$ & $3-8.9$ & & & \\
\hline \multicolumn{7}{|c|}{ Interleukin 6 (pg/ml) } \\
\hline Mean \pm SD & $1.95 \pm 0.44$ & $2.5 \pm 0.46$ & $3.54 \pm .31$ & $F^{\mathrm{a}} 50.85$ & $<0.001$ & $0.001^{b}<0.001^{c}<0.001^{d}$ \\
\hline Range & $1.3-2.8$ & $1.8-3.2$ & $3.2-4.1$ & & & \\
\hline
\end{tabular}

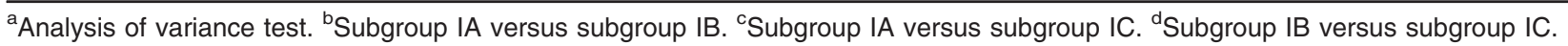

${ }^{e}$ Kruskal-Wallis test. HbA1c, glycated hemoglobin A1c; LSD, least significant difference. It means that the value is statistically significant $(P<0.05)$.

Table 4 Comparison of laboratory results of the type 2 diabetes mellitus subgroups

\begin{tabular}{|c|c|c|c|c|c|c|}
\hline Variables & Subgroup IIA $(N=13)$ & Subgroup IIB $(N=13)$ & Subgroup IIC $(N=13)$ & Test & $P$ & LSD \\
\hline \multicolumn{7}{|c|}{ Fasting blood glucose (mg/dl) } \\
\hline Mean \pm SD & $158.2 \pm 30.8$ & $176.2 \pm 47.9$ & $156.4 \pm 35$ & $F^{\mathrm{a}} 1.05$ & 0.36 & $0.24^{b} 0.91^{c} 0.20^{d}$ \\
\hline Range & $127-245$ & $85-245$ & $110-245$ & & & \\
\hline \multicolumn{7}{|c|}{$2 \mathrm{~h}$ postprandial (mg/dl) } \\
\hline Mean \pm SD & $241.9 \pm 32.2$ & $264.6 \pm 43.6$ & $249.2 \pm 41.7$ & $F^{\mathrm{a}} 1.12$ & 0.34 & $0.15^{\mathrm{b}} 0.64^{\mathrm{c}} 0.33^{\mathrm{d}}$ \\
\hline Range & $205-285$ & 210-340 & $210-320$ & & & \\
\hline \multicolumn{7}{|l|}{$\mathrm{HbA} 1 \mathrm{c} \%$} \\
\hline Mean \pm SD & $7.35 \pm 0.17$ & $7.83 \pm 1.54$ & $7.92 \pm 0.5$ & $F^{\mathrm{a}} 1.38$ & 0.27 & $0.20^{b} 0.13^{c} 0.80^{d}$ \\
\hline Range & $7.1-7.6$ & $6.4-12.5$ & $7-8.5$ & & & \\
\hline \multicolumn{7}{|c|}{ Creatinine (mg/dl) } \\
\hline Mean \pm SD & $0.98 \pm 0.14$ & $1.05 \pm 0.20$ & $1.38 \pm 0.20$ & $F^{\mathrm{a}} 17.19$ & $<0.001$ & $0.40^{b}<0.001^{c}<0.001^{d}$ \\
\hline Range & $0.7-1.2$ & $0.8-1.5$ & $1-1.6$ & & & \\
\hline \multicolumn{7}{|l|}{ Urea $(\mathrm{mg} / \mathrm{dl})$} \\
\hline Mean \pm SD & $27.92 \pm 5.2$ & $29.38 \pm 5.7$ & $46.15 \pm 7.83$ & $F^{\mathrm{a}} 33.27$ & $<0.001$ & $0.56^{b}<0.001^{c}<0.001^{d}$ \\
\hline Range & $20-38$ & $20-41$ & $32-60$ & & & \\
\hline \multicolumn{7}{|c|}{ Urinary albumin excretion rate $(\mu \mathrm{g} / \mathrm{min})$} \\
\hline Mean \pm SD & $10.38 \pm 5.18$ & $178.3 \pm 8.85$ & $467.7 \pm 90.8$ & $K^{\mathrm{e}} 33.83$ & $<0.001$ & $<0.001^{\mathrm{b}}<0.001^{\mathrm{c}}<0.001^{\mathrm{d}}$ \\
\hline Range & $4-19$ & $128-200$ & $220-620$ & & & \\
\hline \multicolumn{7}{|c|}{ Highly sensitive C-reactive protein (mg/l) } \\
\hline Mean \pm SD & $2.53 \pm 0.72$ & $3.98 \pm 0.79$ & $5.5 \pm 0.04$ & $K^{\mathrm{e}} 22.83$ & $<0.001$ & $0.009^{b}<0.001^{c} 0.006^{d}$ \\
\hline Range & $0.9-3.5$ & $2.4-5$ & $3-8.7$ & & & \\
\hline \multicolumn{7}{|c|}{ Interleukin 6 (pg/ml) } \\
\hline Mean \pm SD & $1.88 \pm 0.43$ & $2.41 \pm 0.41$ & $3.42 \pm 0.34$ & $F^{\mathrm{a}} 52.18$ & $<0.001$ & $0.001^{\mathrm{b}}<0.001^{\mathrm{c}}<0.001^{\mathrm{d}}$ \\
\hline Range & $1.20-2.7$ & $1.9-3.1$ & $3-4$ & & & \\
\hline
\end{tabular}

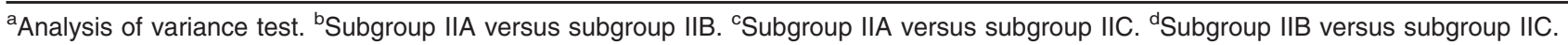
${ }^{\mathrm{e}}$ Kruskal-Wallis test. HbA1c, glycated hemoglobin A1c; LSD, least significant difference. It means that the value is statistically significant $(P<0.05)$. 
Table 5 Pearson's correlation between highly sensitive C-reactive protein and other parameters in the studied groups

\begin{tabular}{|c|c|c|c|c|c|c|}
\hline \multirow[t]{3}{*}{ Variables } & \multirow{2}{*}{\multicolumn{2}{|c|}{ Control $(N=13)$}} & \multicolumn{4}{|c|}{ Patients } \\
\hline & & & \multicolumn{2}{|c|}{ Subgroup I $(N=39)$} & \multicolumn{2}{|c|}{ Subgroup II $(N=39)$} \\
\hline & $r$ & $P$ & $r$ & $P$ & $r$ & $P$ \\
\hline Age & 0.04 & 0.90 & -0.03 & 0.88 & 0.14 & 0.40 \\
\hline Duration of disease & - & - & 0.51 & $<0.001$ & 0.56 & $<0.001$ \\
\hline Waist-hip ratio & -0.31 & 0.31 & -0.22 & 0.18 & -0.20 & 0.22 \\
\hline Systolic blood pressure & -0.15 & 0.63 & 0.47 & 0.002 & 0.50 & $<0.001$ \\
\hline Diastolic blood pressure & -0.42 & 0.15 & 0.34 & 0.04 & 0.42 & 0.008 \\
\hline Fasting blood glucose & 0.23 & 0.45 & -0.06 & 0.74 & -0.09 & 0.57 \\
\hline $2 \mathrm{~h}$ postprandial & 0.20 & 0.52 & -0.02 & 0.89 & -0.03 & 0.87 \\
\hline $\mathrm{HbA1c}$ & -0.04 & 0.89 & 0.23 & 0.16 & 0.25 & 0.13 \\
\hline Creatinine & -0.13 & 0.68 & 0.44 & 0.005 & 0.35 & 0.03 \\
\hline Urea & -0.34 & 0.26 & 0.49 & 0.002 & 0.47 & 0.02 \\
\hline Urinary albumin excretion rate & 0.16 & 0.60 & 0.59 & $<0.001$ & 0.59 & $<0.001$ \\
\hline Cholesterol & -0.01 & 0.98 & 0.18 & 0.28 & 0.15 & 0.36 \\
\hline Triglyceride & -0.18 & 0.55 & 0.08 & 0.62 & -0.002 & 0.99 \\
\hline HDL & -0.15 & 0.61 & 0.16 & 0.32 & 0.18 & 0.28 \\
\hline LDL & 0.17 & 0.59 & 0.14 & 0.41 & 0.13 & 0.42 \\
\hline Interleukin 6 & 0.33 & 0.27 & 0.52 & $<0.001$ & 0.54 & $<0.001$ \\
\hline
\end{tabular}

$\mathrm{HbA1c}$, glycated hemoglobin A1c; HDL, high-density lipoprotein; LDL, low-density lipoprotein. It means that the value is statistically significant $(P<0.05)$.

Table 6 Pearson's correlation between interleukin 6 and other parameters in the studied groups

\begin{tabular}{|c|c|c|c|c|c|c|}
\hline \multirow[t]{3}{*}{ Variable } & \multirow{2}{*}{\multicolumn{2}{|c|}{ Control $(N=13)$}} & \multicolumn{4}{|c|}{ Patients } \\
\hline & & & \multicolumn{2}{|c|}{ Subgroup I $(N=39)$} & \multicolumn{2}{|c|}{ Subgroup II $(N=39)$} \\
\hline & $r$ & $P$ & $r$ & $P$ & $r$ & $P$ \\
\hline Age & 0.03 & 0.92 & -0.02 & 0.90 & 0.28 & 0.90 \\
\hline Duration of disease & - & - & 0.74 & $<0.001$ & 0.75 & $<0.001$ \\
\hline Waist-hip ratio & 0.16 & 0.60 & -0.52 & $<0.001$ & -0.51 & $<0.001$ \\
\hline Systolic blood pressure & -0.35 & 0.24 & 0.40 & 0.01 & 0.34 & 0.04 \\
\hline Diastolic blood pressure & -0.49 & 0.09 & 0.20 & 0.22 & 0.34 & 0.03 \\
\hline Fasting blood glucose & 0.07 & 0.82 & -0.10 & 0.54 & -0.19 & 0.25 \\
\hline $2 \mathrm{~h}$ postprandial & 0.003 & 0.9 & 0.002 & 0.99 & -0.03 & 0.86 \\
\hline $\mathrm{HbA1c}$ & -0.004 & 0.99 & 0.10 & 0.53 & 0.13 & 0.44 \\
\hline Creatinine & 0.50 & 0.08 & 0.54 & $<0.001$ & 0.56 & $<\mathbf{0 . 0 0 1}$ \\
\hline Urea & 0.22 & 0.48 & 0.60 & $<0.001$ & 0.65 & $<0.001$ \\
\hline Urinary albumin excretion rate & 0.22 & 0.48 & 0.85 & $<0.001$ & 0.87 & $<0.001$ \\
\hline Cholesterol & 0.26 & 0.40 & -0.06 & 0.70 & -0.11 & 0.51 \\
\hline Triglyceride & -0.12 & 0.69 & 0.07 & 0.67 & -0.03 & 0.85 \\
\hline HDL & 0.34 & 0.26 & 0.14 & 0.38 & 0.15 & 0.37 \\
\hline LDL & -0.14 & 0.63 & 0.23 & 0.15 & 0.25 & 0.12 \\
\hline Highly sensitive C-reactive protein & 0.33 & 0.26 & 0.52 & $<0.001$ & 0.54 & $<0.001$ \\
\hline
\end{tabular}

$\mathrm{HbA1c}$, glycated hemoglobin A1c; HDL, high-density lipoprotein; LDL, low-density lipoprotein. It means that the value is statistically significant $(P<0.05)$.

diabetes in comparison with normal nondiabetic personnel.

Our work supports the results of Shelbaya et al. [8] who concluded that IL-6 and hs-CRP were sensitive markers for DN in Egyptian patients with T1DM. In addition, Dalla Vestra et al. [5] had demonstrated that low-grade inflammation is associated with nephropathy status and glomerular basement membrane thickening in T2DM. In contrast,
Bertoni et al. [10] and Wang et al. [11] showed no significant difference in the studied groups regarding IL-6 and other inflammatory markers, as they supposed that most patients were undergoing a course of treatment using many drugs, which changed the effects of inflammation, like metformin, statins, and antihypertensive medications.

We found that the results of this study embraced the findings of Schwab et al. [12] who conducted a study 
on children, adolescents, and young adults with T1DM, and revealed a significant correlation between IL-6, hs-CRP, and the duration of DM.

Dogan et al. [13], conducted a study on 27 children with T1DM and found a significant positive correlation between IL-6, hs-CRP, and HbA1c. In contrast, the current study showed no correlation in either patients with T1DM or those with T2DM with blood glucose or HbA1c, which may be attributed to the better blood glucose control in participants of this study. Schram et al. [14], proved that association between UAER and HbA1c is independent and suggests that factors other than bad glycemic control may be involved in the pathophysiology of early renal impairment in patients with T2DM. In addition, Czyzewska et al. [7], concluded that in patients with T2DM with better metabolic control, CRP was a sensitive marker of albuminuria.

We confirmed similar results to a study made by Choudhary and Ahlawat [6], who proved the effect of inflammation, mainly subclinical type, in the occurrence of early renal injury especially in T2DM, owing to the significant association between UAER and inflammatory cytokines. In addition, Piccirillo et al. [15], proved that low-degree of inflammation was already found in the early stage of microalbuminuria, and low-grade inflammatory markers could play a role in the beginning, and the development of renal insult in patients with T2DM. Moreover, Stehouwer et al. [16], proved in a study of 328 patients with T2DM that urinary albumin levels increased by $1.02 \mathrm{mg} / 24 \mathrm{~h}$ (95\% confidence interval, 1.01-1.27) for each increase in CRP of $1 \mathrm{mg} / 1$ over 10 years of follow-up. The same was found by Domingueti et al. [9], who suggested that an interrelation between inflammation and hypercoagulability might contribute to the development and progression of renal disease in T1DM.

Wadwa et al. [17] reported that lipid profiles showed a significant positive correlation with hs-CRP and IL-6. However, in the present study, no correlation was detected in both patients with T1DM and those with T2DM without possible explanation.

One of the strengths of our study was the inclusion of both T1DM and T2DM, sex-matched patients, in a direct comparison between them, in addition to in-group analysis according to UAER categories. In addition, our results showed a positive correlation between IL-6 and hs-CRP. However, a larger scale study is needed to validate our results on a national level and to evaluate the cost-effectiveness of using these markers for screening of early DN.

\section{Conclusion}

IL-6 and hs-CRP may be used as sensitive markers for the development of DN in patients with T1DM and T2DM. We recommend the use of IL-6 and hs$\mathrm{CRP}$ in the routine follow-up of diabetic patients.

\section{Financial support and sponsorship Nil.}

\section{Conflicts of interest}

There are no conflicts on interest.

\section{References}

1 Donate-Correa J, Martín-Núñez E, Muros-de-Fuentes M, Mora-Fernández C, Navarro-González JF. Inflammatory cytokines in diabetic nephropathy. J Diabetes Res 2015; 2015:948417.

2 Chang MK, Binder CJ, Torzewski M, Witztum JL. C-reactive protein binds to both oxidized LDL and apoptotic cells through recognition of a common ligand: phosphorylcholine of oxidized phospholipids. Proc Natl Acad Sci 2002; 99:13043-13048.

3 Tanaka T, Kishimoto T. Targeting interleukin-6: all the way to treat autoimmune and inflammatory diseases. Int J Biol Sci 2012; 8: 1227-1236.

4 Avci E, Çakir E, Cevher SC, Yaman H, Agilli M, Bilgi C. Determination of oxidative stress and cellular inflammation in patients with diabetic nephropathy and non-diabetic nephropathy being administered hemodialysis treatment due to chronic renal failure. Ren Fail 2014; 36: 767-773.

5 Dalla Vestra M, Mussap M, Gallina P, Bruseghin M, Cernigoi AM, Saller A, et al. Acute-phase markers of inflammation and glomerular structure in patients with type 2 diabetes. J Am Soc Nephrol 2005; 16(Suppl 1): S78-S82.

6 Choudhary N, Ahlawat RS. Interleukin-6 and C-Reactive protein in pathogenesis of diabetic nephropathy new evidence linking inflammation, glycemic control, and microalbuminuria. Iran J Kidney Dis $2008 ; 2: 72-79$

7 Czyzewska J, Wasilewska K, Kaminska J, Koper O, Kemona H, Jakubowska I. Assess the impact of concentrations of inflammatory markers IL-6, CRP in the presence of albuminuria in patients with type 2 diabetes. Pol Merkur Lekarski 2012; 32:98-102.

8 Shelbaya S, Amer H, Seddik S, Allah AA, Sabry IM, Mohamed T, et al. Study of the role of interleukin- 6 and highly sensitive C-reactive protein in diabetic nephropathy in type 1 diabetic patients. Eur Rev Med Pharmacol Sci 2012; 16:176-182.

9 Domingueti CP, Fóscolo RB, Reis JS, Campos FM, Dusse LM, Carvalho $\mathrm{MD}$, et al. Association of haemostatic and inflammatory biomarkers with nephropathy in type 1 diabetes mellitus. J Diabetes Res 2016; 2016: 2315260.

10 Bertoni AG, Burke GL, Owusu JA, Carnethon MR, Vaidya D, Barr RG, et al. Inflammation and the incidence of type 2 diabetes: the MultiEthnic Study of Atherosclerosis (MESA). Diabetes Care 2010; 33:804-810.

11 Wang X, Bao W, Liu J, OuYang YY, Wang D, Rong S, et al. Inflammatory markers and risk of type 2 diabetes: a systematic review and meta-analysis. Diabetes Care 2013; 36:166-175.

12 Schwab KO, Doerfer J, Hecker W, Grulich-Henn J, Wiemann D, Kordonouri $\mathrm{O}$, et al. Spectrum and prevalence of atherogenic risk factors in 27,358 children, adolescents, and young adults with type 1 diabetes: cross-sectional data from the German diabetes documentation and quality management system (DPV). Diabetes Care 2006; 29: 218-225.

13 Dogan Y, Akarsu S, Ustundag B, Yilmaz E, Gurgoze MK. Serum IL-1 $\beta$, IL-2, and IL-6 in insulin-dependent diabetic children. Mediators Inflamm 2006; 2006:2315260. 
14 Schram MT, Chaturvedi N, Schalkwijk CG, Fuller JH, Stehouwer CD, EURODIAB Prospective Complications Study Group. Markers of inflammation are cross-sectionally associated with microvascular complications and cardiovascular disease in type 1 diabetes - the EURODIAB Prospective Complications Study. Diabetologia 2005; 48:370-378.

15 Piccirillo LJ, Gonçalves MD, Clemente EL, Gomes MD. Markers of inflammation in type 1 diabetic patients. Arq Bras Endocrinol Metabol 2004; 48:253-260.
16 Stehouwer CD, Gall MA, Twisk JW, Knudsen E, Emeis JJ, Parving HH. Increased urinary albumin excretion, endothelial dysfunction, and chronic low-grade inflammation in type 2 diabetes: progressive, interrelated, and independently associated with risk of death. Diabetes 2002; 51:1157-1165.

17 Wadwa RP, Kinney GL, Maahs DM, Snell-Bergeon J, Hokanson JE, Garg SK, et al. Awareness and treatment of dyslipidemia in young adults with type 1 diabetes. Diabetes Care 2005; 28:1051-1056. 